\title{
REVIEW ARTICLE: \\ THE ROLES OF ASSESSMENT IN CURRICULUM PRACTICE AND ENHANCEMENT OF LEARNING
}

\author{
Fisseha Mikre
}

\begin{abstract}
Assessment is indispensable component of curriculum practice. In systems of education, one of the prime considerations of administrators, teachers, and students alike are the outcomes of learning, what ability students can demonstrate because of increase in their knowledge and changes in understanding because of experiences in school or college. Concern for how learning takes place in higher learning institutes and how instruction and assessment affect the quality of learning is desirable, for students need to acquire knowledge and competencies that can be transferable in the work place. Therefore, educators need to think carefully about the quality of curriculum practice and learning assessment in higher education. Much of current teaching and assessment in higher learning institutes seems to induce passive, reproductive form of learning that is contrary to the aims of instructors themselves. Most of the time instructors emphasize on factual knowledge, bind students too firmly within currently acceptable theoretical framework, and do the same while assessing learning. To the contrary, transferable skills valued by employers such as problem solving, communication skills, and working effectively with others are highly essential. Educators are suggesting that instructors will be more effective if assessment is integral to teaching and how learning activities are structured. Performance assessment, portfolios, authentic assessment and student self and peer assessment together with feedback and comments have been advocated as procedures that align assessment with current constructivist theories of learning and teaching. For instance, teachers are responsible for providing feedback that students need in order to re-learn and refine learning goals. Hence, this article reviews, roles of assessment in operating and experiencing the curriculum, importance of continuous assessment for enhancement of student learning, and the roles of feedback and comments for curriculum practice and learning enhancement.
\end{abstract}

* Psychology Department, JU. 


\section{INTRODUCTION}

In this review article, literature was searched with respect to the roles of assessment in curriculum practice and enhancement of learning. The review consists of three sections, namely: Assessment as component of the curriculum, continuous assessment for learning, and the importance of feedback and comments in assessed work. In the first section, assessment as essential components and pillar in the operation and implementation of curriculum intentions is emphasized. The second section focuses on continuous assessment for learning. Continuous assessment involves assessment procedures designed to serve the purpose of promoting and enhancing students' learning. In the section, assessment as a means of curriculum operation and experience in everyday classroom context is also discussed.

Moreover, the section focuses on roles of course instructor in integrating assessment with everyday classroom instruction, and in facilitating appropriate learning environments. Assessment without feedback and comments is less likely to enhance student learning. Therefore, the third section discusses the importance of providing feedback and comments on assessed work. Hence, this review article attempts to answer the following questions to pin point the role of assessment in curriculum practice and enhancement of learning.

1. What is the role of assessment in the operation and experiential curriculum (the curriculum as experienced by the student and related to their prior knowledge and experience)?
2. How important is continuous assessment in curriculum operation and enhancement of student learning?

3. What are the effects of feedback and comments on assessed work in curriculum practice and enhancement of learning?

\section{Assessment as component of curriculum practice}

Van den Akker (2003) described assessment as essential component of the curriculum practice. Assessment is a process for obtaining information in curriculum operation in order to make decisions about student learning, curriculum and programs, and on education policy matters. Because of this, educators strongly suggest that assessment and curriculum integrated in the continuous cycle of curriculum planning, operation, implementation, and evaluation. For example, the attained curriculum both the experienced and the learned are determined by assessment procedures. Assessment procedures in formative ways could also help in the operation of the curriculum. Instructors make a number of decisions. These include managing instruction, assessing student competence, placing students to levels of education programs, assigning grades to students, guiding and counseling, selecting students for education opportunities, certifying competence and so on. All these can be possible when there are effective assessment procedures in the curriculum operation and practice.

In assessment of students' learning progress and competence attained, there is a need to gather variety of information and determine the degree to which students have attained the learning targets intended in the curriculum. Information for this, gathered using variety of techniques such 
as formal and informal observation of students while learning, paper-and-pencil tests, lab work, performance on assignments, research projects, presentation, and so forth. Educators advise a plan for assessment for any curriculum at program, course, and lesson level, even though it is often times over looked. As Pratt (1998) stated it, to assure student achievements and grades that can reflect the learning priorities established, assessment needs to be carefully planned, conducted, and subject to ongoing analysis, evaluation, and improvement. Ideally curriculum targets (knowledge and competence of learners), assessment, and instruction are all parts of an integrated whole.

There is a general belief that assessment is handmaiden to the instruction process in the operation, and experience of the curriculum. Nevertheless, significant proportion of students those particularly in the higher institutes perceive assessment as a basic source of power for instructors and of stress and disempowerment for themselves. As discussed by (Pratt, 1998; Haladyna \&Downing, 2004), when students step from one term to the other, they become more dissatisfied with, remain cynical and suspicious about assessment practices, increasingly viewing assessment procedures as unfair and a means to distribute reward and punishment. As the current practice of assessment in higher learning institutes reveals, instructors, in most cases mandated to influence assessment choices and practices. Since results of assessment decisively affect the academic competence and occupational future of students, instructors are required to create productive learning environments, which make assessment integral to the instructional process. In productive learning environments both students and teachers experiment, try out ideas, tackle and puzzle over problems, think, reflect, discuss, ask questions, look up information, surprise themselves and each other in the curriculum operation process(Pratt,1998).

As desirable curriculum component, assessment has several purposes among which are: It directs the instructional process. Assessment as a pervasive observation, monitoring, and transaction that takes place in classrooms is important kind of educational assessment. In such case, instructors determine whether a lesson is going well and students are catching by observation during learning, student responses to questions, and student interactions (Nitko, 2004).

In directing instruction, assessment is a means to diagnose learning difficulties; it helps the instructor identify the learner's areas of strength and weakness so that he/she plans instruction to build on the one and remediate the other in formal and informal ways. Secondly, assessment provides feedback about success of a study program. Information from the assessment of student learning utilized in program evaluation (Pratt, 1998).

Thirdly, assessment reports individual learning achievements or grades for various parties including students, parents, education institutes to which students may apply for admission, potential employers, occupational, and professional licensing bodies. As stated by Nitko (2004), results from classroom learning activities, quizzes, tests, class projects, assignment papers, informal observations on how well the student has attained the intended learning targets can be used to grade students for a lesson, or unit, a marking period, or course.

Moreover, assessment directs students to instructional priorities and influences their approach to experience course curriculum. Informal teacher questions, tests, and 
examinations indicate students, which parts of the curriculum have priority. For instance if tests examine trivial information, learners focus becomes on learning strategies aimed at factual recall and recognition of knowledge. Students change their approach of curriculum perception and experience for tests requiring substantive knowledge and deep understanding. Furthermore, assessment is also useful in enhancing student motivation, self-concept, and sense of selfefficacy. When assessment, designed to produce real success in student learning and curriculum experience, frequent use stimulates student confidence and willingness to learn. Meherns and Lehman (1991) described the importance of assessment in increasing student motivation towards a course, encouraging good study habits, and in providing feedback that identifies strengths and weaknesses of learners. Teachers can use assessment to guide decisions about the learners. The better the diagnostic and achievement data from assessment the teacher has about his/her students, the more appropriate the guidance he/she will be able to provide learners about their learning, and about their academic and occupational choices. Therefore, instructors in higher institutes should aware the salient role of assessment among the curriculum components and internalize proper skills and applications to effectively implement curriculum at course level.

\section{Continuous Assessment for Learning}

Continuous assessment practiced less than summative assessment in the classroom context. As put by Careless (2004), faculty members in higher learning institutes tend to concentrate on theoretical knowledge at the expense of practical and procedural knowledge and test students knowing that. Such testing limits students focus on learning facts, and it helplessly restricts them in the outside world, rather than what will really be substantive, helpful, and transferable to the work place (Brown \& Glaser, 1999). Improvement on assessment practice raises students' learning and achievement. Moreover, learning standards rose through continuous assessment for learning. When instructors change their practice in assessment, students change their behaviour so that everyone shares responsibility for the students' learning and improvement of learning environments. Nevertheless, there are challenging problems in practicing assessment that can improve learning standards and achievement. Three main problems identified by Black and William (2004) with respect to assessment for learning in higher learning institutes are the following:

- The assessment methods that instructors use are not effective in promoting good learning,

- Grading practices tend to emphasize competition rather than personal improvement, and

- Assessment feedback, if at all exists often has negative impact particularly on low-achieving students, who are led to believe that they lack ability and so are not able to learn.

Furthermore, Diamond (1998) described the fundamental problem in assessment practices of higher education courses as the mismatch between the learning targets established and the methods and criteria instructors use to judge and grade their students. In most cases, the learning goals include higher-order reasoning abilities, but the assessment procedures most frequently used focus on simple recall and recognition of the learned content. 
Any assessment practice for which the first priority in its design and practice is serving the purpose of promoting students' learning is described as continuous assessment (assessment for learning). It differs from assessments designed primarily to serve the purpose of accountability, ranking students, or certifying their competence. An assessment practice is more helpful for enhanced learning if it provides information that instructors and students can use as feedback in their progress and one another and in modifying the instructional process. Such assessment is also called 'assessment for learning' when the evidence from the assessment is used to adapt the teaching work to meet learning needs and difficulties (Black \& Wiliam, 1998).

As in the recent understandings, assessment is not something that follows and is separable from learning. Rather assessment shapes, and is part of the learning process. Much has been written about the need to integrate assessment practices with instruction to enhance student learning (Wright, et.al, 1997). Assessment and instruction should be seamless, each contributing to the goal of improved learning. Moreover, effective instructors integrate assessment and teaching, and how learning activities are structured. Despite this suggestion, teachers in higher learning institutes continue to use assessments that measurement experts contend are not consistent with best practices (Wright et.al, 1997). Furthermore, assessment procedures in higher learning institutes have been criticized for putting a premium on the reproduction of knowledge and passivity of mind at the expense of critical judgement and substantive competence (Black \& Wiliam, 1998).

For instance, the introduction of multiplechoice tests into education systems have been criticized for encouraging teachers to set learning tasks that promote de-contextualized, rote learning and that narrows the intended curriculum to basic skills with low cognitive demands. In contrast to this, the proliferation of service industries and the changing character of work have created demands for transferable skills such as those of communication, information retrieval, problem solving, critical analysis, self-monitoring and self-assessment. Because of this, there is a fast growing interest in the more formative, holistic, contextualized forms of assessment, often described as 'authentic' or performance assessments. However, as argued by Black and William (1998), it remains the case that traditional forms of assessment are not easily replaced, embedded as they are in complex histories, cultures, and power relations of school societies. Shepard (2001) has also suggested that traditional assessment perspectives, based on behaviourist theories of learning and conventional psychometric principles conflict with implications of assessment for learning represented by the emerging cognitive and constructivist learning paradigms.

According to Wright et.al (1997) Performance assessment, portfolios, authentic assessment, student selfassessment and peer assessment are considered as procedures that align with current constructivist theories of learning and teaching. In order to have salient contributions to the curriculum implementation process, assessment procedures should define what students regard important in the learning, how they spend time, and how they come to see themselves as students. Often times, students complain on assessment procedures used by their instructors. They reported that curriculum is not shaping the assessment; rather assessment is always shaping curriculum implementation and 
embodying the purpose of higher education. As a result, students fail to experience the intended curriculum as a whole. Many of students' comments in relation to assessment were about utility of feedback and comments on assessed work, which in most cases fell below their expectations. An investigation made by James (2003) indicated that a number of major effects were associated with the act of being assessed, including serious consequences for students self-perception and levels of confidence. The investigation also revealed that, for many students, the focus of disappointment was lack of information to base decisions about what they should do differently in order to raise level of their competence and marks in assessed work. For others, the concern is in identifying what they should do to achieve high marks. End of course examinations are rarely discussed or made available so that students could use them to improve their knowledge and skills.

As a pillar to the education process, assessment plays significant roles in implementing curriculum. For this to happen, the practice should be based on important guiding principles. James (2003) forwarded the following as guiding principles for conducting continuous assessment (assessment for learning):

- Ensure that assessment procedures promote and reward desired learning activities and outcomes,

- Communicate assessment requirements clearly to students, and

- Strive for providing effective feedback and comment to students on a continuous basis

For instance, with the first principle, instructors are advised to draw on Bloom's taxonomy to divide the intellectual skills into three broad areas (recall and recognition, comprehension and application, critical thinking and problem solving). With respect to the second principle, James (2003:65) puts the following:

Assessment procedures in higher education are likely to become increasingly open to scrutiny to candidates, and to candidates appeals. The need for commonly agreed marking procedures and techniques is obvious, if collective responsibility for candidates is maintained, full openness between colleagues and demonstrable internal consistency of courses and related assessment procedures are vital importance.

Of course, there can be a problem in over generalizing good assessment procedures for learning practice. As with teachers themselves, different subject disciplines (eg. Engineering versus Psychology) may have different pedagogic assumptions. Thus, while the general principles apply across all subjects, the ways in which they manifest themselves in different subjects may differ (Black \& William, 2004). On the other hand, assessment procedure changes perceived improvements in one course might be seen as impractical or irrelevant in another. However, teachers who have good intentions for their assessment practice, and who always attempt to make it integral to teaching becomes more effective. Despite their good intentions, most teachers set assessment tasks that encourage a narrow instrumental approach to learning emphasizing the reproduction of what is presented, at the expense of critical thinking, deep understanding, and independent activity (Filer, 2003). In contrast to this, Boud (1990) suggests some alternative developments in the assessment of students in higher education. These include careful monitoring of assessment practices to see how valid they are in the eyes of students, 
challenging existing assessment procedures because they do not prepare reflective practitioners needed in the world of work. According to (Meherns \& Lehman, 1991 \& Nitko, 2004), quality teaching and quality assessment are intertwined; together they greatly improve students' opportunities to learn. Teaching can be most effective when teaching activities, learning targets, and assessment procedures are all synchronized. For this, the assessment procedures should specify the important learning targets. As Nitko (2004) states it, to be valid, assessment procedures must match the learning targets and well communicated to students. Otherwise, the validity of assessment for learning results falls down when even some of the tasks do not match the stated learning targets.

Researchers in education estimated that effective teachers may spend from one third to one half of their time in assessment related activities (Stiggeins, 1992). While teaching, teachers are expected to pay attention on the importance of assessment in the classroom. With respect to this, Nitko (2004: 4) suggested four key questions that teachers need to ask themselves during the instructional process and while implementing continuous assessment. The questions are:

- Is my lesson going well? Are students progressing in the learning? For this, assessment procedures such as observation of students during learning activities, student responses to questions, and observing student interactions can be employed,

- What should I do to make this learning activity work better? Diagnosis of the types of errors students make and identifying which students are not participating or are acting inappropriately, are some of the assessment procedures used,
- What feedback should I give each student about how well he/she is learning? The assessment procedures used to answer this question are informal observation and experience on the amount and type of praise different students require, information about how close each student has come to achieving the learning targets, home work and quiz results, and interviewing students, and

- Are my students ready to move to the next activity in the learning sequence? Informal observation and checking students' completed work, questioning students about their understanding, students' home work, assignments, quiz, test results, and grades earned are some useful assessment procedures to decide whether students can move to the next learning sequence or require some remedial instruction.

The teacher in the classroom must use variety of assessment procedures to help students attain learning targets stipulated in the course curricula. Most teachers, however, do believe and use pencil-andpaper tests as the only assessment procedure to be used. Meherns and Lehman (1991) argue that classroom evaluation instruments must not be restricted to conventional pencil-and-paper achievement tests; rather they must use rating scales, checklists, and observational techniques and so forth. Continuous assessment procedures (assessment for learning) are more practical in every day's classroom context. These assessments are activities in which students engage, and that led teachers and students an idea of where the student stands in relation to knowledge and skills in a particular course. They are formative in nature. They can be tests, 
assignment papers, presentations, projects, products, collaborative works and so forth

(Smith, 2003). Classroom assessment has historically been viewed as an issue more closely aligned with curriculum and instruction than with measurement theory, because measurement professionals are more interested in issues of test development and technical qualities of tests than in classroom assessment. As stated by Smith (2003) and Shepard (2001), at present, there is a trend of moving away from traditional measures of classroom assessment toward variety of new approaches that are more closely linked to instructional practices and less closely linked to concerns for technical quality of assessment procedures such as reliability and validity. Shepard (2001) also argues that technical qualities such as reliability and validity are less critical for classroom assessment since errors in instructional decision can be filtered through additional information gathered in the classroom setting.

In the classroom context, the first goal of assessment is essentially formative and learning improvement in nature. It is viewed as a tool to inform the teacher about strengths and weaknesses of individual students as well as the class as a whole, and to assist students understand their own progress. Therefore, traditional notions of the technical qualities of assessment are not appropriate for classroom-based assessments and there is a need to develop new conceptualizations of these qualities in particular validity and reliability (Smith, 2003; Shepard, 2001; Brookhart, 1997). Instead of using traditional technical qualities of assessment, Stiggins (2001) suggested to use the phrase 'high quality classroom assessment' by avoiding validity and reliability. On the other hand, good classroom assessments are not only measures of learning, but they are also genuine episodes of learning itself (Wolf, 1993). The more performance based the assessments are in the classroom, the more the line between assessment and instruction blurs. To create a good classroom assessment environment, the teacher has to consider the assessment methods to be used, the criteria for selecting them, their quality, the use of feedback and comments, the teachers' perception of the students, and students' involvement as self and peer assessors (Hoover, 2003). Recent developments in assessment procedures have also encouraged having students participate in the generation and even in the scoring of learning activities and assessment tasks, or having choices in aspects of the learning activity (Smith, 2003). In describing the advantages of classroom assessment environment for the student, (Brookhart, 2003) stated that:

From the students' point of view, classroom assessment information is not merely information about himself or herself, rather, it forms a major part of his/her learning life, becoming part of the lesson he or she is expected to learn, the relationship he/she has with the teacher and the subject matter, and relationship with peers.

If we expect students benefit from classroom assessments, three things must happen. First, they must develop concept of their learning goal, that was originally is the teacher's, but with learning the student internalizes it. Second, students must develop ability to monitor their work and compare actual with desired performance. Third, students must develop the ability to act in such a way as to close the gap, which involves setting their own learning goals. In this case, teachers are responsible to provide feedback that students need, and teachers provision of the feedback is part of the formative assessment. For this, teachers should get trained about classroom assessments in relation to both instruction 
and classroom management, not simply as a decontextualized application of measurement principles (Brookhart, 1999). In relation to this, Stiggins (2001) maintained that crucial instructional decisions made in the classroom every day, not just in a semester or once a year, and must be based on accurate evidences of every days learning for the sake of student success. The formative assessment process itself is part of the learning because, it is in this process that students come to understand the standard quality work with which their work is compared. This differs from summative assessment in which the assessor is the only one who necessarily has to understand the standard (Brookhat, 2003). Summative assessment requires that teachers become members of community of practice, where as formative assessment requires that learners become members of same community of practice (Black \& William, 1998). For several reasons, all classroom assessments are formative. Students see classroom assessment as a demonstration of what they were supposed to learn.

They should recognize the language of assessment as language of instruction (Brookhart, 2003). The teacher can have variety of assessment methods to use in the classroom. For instance, Observation is greatly used by experienced teachers to identify students progressing or having difficulties in their learning. Some teachers maintain a logbook in which they record observations on students' daily work habits and progress they show in learning, particularly when working in groups. Portfolio or records of work are also another important classroom assessment used by teachers. Portfolio is a kind of file in which a students' written work, or the best examples of it are kept. Portfolio could be used to build record of students' lab reports in science, and how it would have relevance in such subjects as drafting, mathematics, languages, history, or geography. Portfolios provide cumulative record of student performance that show learning progress over time in much detail and substance than a mere list of scores. Portfolios enable the teacher to make much more specific instructional plans and recommendations than of standard test scores. Classroom questioning, even though it is more of an instructional strategy than assessment, because of the feedback it provides the teacher, it is a form assessment. Questions before, during, and after instruction, are all known to assist students' learning. Research indicates that more classroom questions focus only on low levels of knowledge (Pratt, 1998). But students learn better if classroom questions are thought-provoking and based on higher order thoughts such as application, analysis and synthesis. In addition, teachers should take care that their questions are evenly distributed among the different ability level learners in a class. Moreover, pausing between the questions and naming a student can help to involve more students in discussions, and increases the quality of student thought and response (Black \& William, 1998, 2004).

Self and peer assessment are essential to learning. Students' self-reflection and their understanding is used to inform future teaching, and their feedback indicates in what areas the teacher needs to spend more time and effort. Assessment may be justified as means of engaging students, to develop and demonstrate students' deep understanding, to communicate individual differences, or to provide students with opportunities to be successful. Brookhart (2001), Shepard (2001), and Stiggins (1999, 2001) maintained that students should be actively involved in assessment through self-evaluation. They argued that students need to monitor their progress by 
applying ongoing meaningful feedback that is helpful in showing them how to meet ultimate learning targets. However, self assessment will happen only if teachers help their students develop the assessment skills, because there is always difficulties to get students think of their work in terms of set of learning targets (Black \& William, 2004). Peer-assessment is also important component to self-assessment that helps realize curricular targets for students' learning. Peer assessment is valuable to attain curricular goals because the interchange is in language that students themselves naturally use. Peer-assessment is also useful in placing the learning task in the hands of students. In this case the teacher is free to observe and reflect on what is happening and frame helpful interventions. In using peer assessment, one teacher described his astonishment as in the following (Black \& William, 2004: 15).

We regularly do peer marking-I find this very helpful indeed. A lot of misconceptions come to the fore, and we often discuss these as we are going over the assessment. I then go over the peer marking and talk to students individually as I go round the room.

Participation in peer assessment and selfassessment is much more than just checking for errors or weaknesses. It involves making explicit what is implicit, and thus it requires students active learning. As one student stated it 'after a student marking my investigation, I can now acknowledge my mistakes easier. I hope that it is not just me who learned from the investigation but the student who marked it did also' (Black \& William, 2004:16). Collaboration between teachers and students and between students and their peers can produce a supportive environment in which students explore their own ideas, hear alternative ideas in the language of their peers, and evaluate them. Research findings also indicated that students trained to prepare for examinations by generating and then answering their own questions outperformed comparable groups who have prepared in conventional ways. Preparing test questions in the form of selfassessment and peer assessment help students develop an overview of the topic (Black \& William, 2004). In general, assessment practices involving students have salient contributions for effective practice of curriculum. For improving classroom practice with respect to assessment, Black and William (2004) have suggested the following:

- Students should be encouraged to keep in mind the aims of their work and to assess their own progress toward meeting these aims as they proceed. Then they will be able to guide their own work and so become independent learners.

- The criteria for assessing any learning achievement must be made transparent to students.

- Students should be taught the habits and skills of collaboration in peer assessment, because both those are of intrinsic value and because peer assessment can help develop, the objectivity required for effective self-assessment.

Furthermore, Stinggins (2001) underscored the importance of student-involved classroom assessment, involving students in the design of assessments, in selfassessment over time, in student record keeping of progress, and in student self reflection to bring effective learning environment. These motivational principles are ones that teachers need to be aware of making appropriate assessment decisions. For example, teachers could be guided by a series of questions about assessment 
procedures that focus on student engagement. These are:

- Are assessment tasks meaningfully related to student interests, backgrounds, and goals?

- Are assessment tasks challenging to students?

- Are students provided with meaningful feedback and comments as they learn?

- How is student engagement determined?

- Is student self-assessment used to help understand their progress and criteria for judging success?

- What skills do students need to be good self-assessors?

McMillan (2003) has also suggested the need for changing the foundation of classroom assessment from one based on scientific measurement to one based on teacher belief, constructivist theories of learning and motivation, and the realities of the classroom. If educators are willing to do this, assessment will be practically enhanced to improve student learning.

\section{The importance of Feedback and Comments}

It is a good practice if assessment procedures provide feedback and comments to students about their learning. In order to improve learning by feedback, learners must be given chance to review both correct and incorrect performances. Feedback should always contain ways for improving learning in the future. Therefore, teachers who show only grades or marks are not providing enough feedback to help improve student learning (Nitko, 2004). Research experiments have established that, while learning is advanced by feedback through comments, giving of numerical scores or grades has a negative effect, in that students ignore comments when marks are also given (Black \& William, 2004). A numerical score or grade does not tell students how to improve in the learning task, so an opportunity to enhance their learning is lost. Comments become useful feedback only if students use those to guide further work, so new procedures are needed. Moreover, to be effective, feedback should cause thinking to take place by students. In relation to this, Black and William (2004) stated that students given marks are likely to see it as way to compare themselves with others (ego involvement); those given only feedback and comments see it as helping them to improve (task involvement). Obviously, the later group outperformed the former. The types of feedback and comment provided are very important to strengthen selfefficacy and motivate students for learning. Students who are told that feedback 'will help you learn', learn more than those who are told that 'how you do tells us how smart you are and what grades you will get'. The difference is greatest for low achievers. In a competitive system, low achievers attribute their performance to lack of ability and high achievers to their effort. In contrast, all students attribute performance to effort in a task -oriented system. In the later case, learning is enhanced particularly for low achievers. A comprehensive review of research studies on feedback found that feedback improved performance in $60 \%$ of the studies. In the cases where feedback was not helpful, the feedback turned out to be merely a judgement or grade with no indication of how to improve learning (Black \& William, 2004). Students value commentary on marked course work for its role in helping them develop their capacities related to academic work. Almost half of the students in higher institutes interviewed on this issue felt that 
some or all of the feedback they received fell short of providing this opportunity (Haladyna \& Downing, 2004). Haladyna and Downing (2004) further stated the presence of strong and shared perceptions among these students about the inadequacy of some of the feedback they received on assessed work, and importantly, about the implications of this for their own development and learning enhancement. The significance of feedback and comments increases when we consider the role of assessment in changes of students' perceptions. In general, feedback given as grade or reward enhances ego involvement rather than task involvement. It can focus students' attention on their ability rather than on the importance of effort, thus damaging the self-esteem of low achievers and leading to problems of learned helplessness. Feedback that focuses on what needs to be done can encourage all believe that they can improve. Such feedback enhances learning both directly through the effort that can ensure and indirectly by supporting to invest such effort. Brookhart $(1997,2001)$ pointed out that when students are able to monitor progress toward meeting challenging but possible learning objectives and by receiving feedback, their self-efficacy is enhanced. It has also been found that successful students engage in selfassessment regularly and actively interpret feedback about their performance as related to course work. Hence, it is an advantage for the enhancement of student learning and provision of quality education if

\section{REFERENCE}

Akker, van den. (2003).Curriculum Perspectives: An Introduction. In .V.dan Akker, W.Kuiper \& U.Hamyer (eds). Curriculum landscapes and Trends (pp1-10) instructors in higher learning institutes emphasize on providing feedback and comment on assessed work of students in the learning process.

\section{CONCLUSION}

Assessment is one essential component of curriculum practice that has salient contribution for effective curriculum operation and implementation. Instructors' recognition for continuous assessment and practice has significance for students learning of substantive knowledge and skill. They should integrate plan for continuous assessment with the instructional process to raise learning standards of students. Moreover, they should devise assessment tasks that practically challenge students, provide feedback and comments as they assess, engage students in the assessment process. However, as discussed in this review article, the current state of assessment, particularly formative/continuous assessment in higher learning programs is not in line with best practices to enhance student learning and actualize curriculum intentions. Furthermore, current changing paradigms of learning such as cognitive and constructivist have implications for awakening and changing instructors' views and practices of assessment in order to prepare competent graduates with marketable knowledge and skill in their specific fields of study. 
Black, P., and William, D. (2004). Inside the Black Box: Phi-Delta Kappan, 86(1):9-21

Boud, D. (1990). Assessment and the Promotion of Academic Values. Studies in Higher Education 15(5): 101-111

Brookhart, S.M. (1997).A theoretical framework for the role of classroom assessment in motivating effort and achievement.

Applied measurement in education 10(2), 161-180

Brookhart, S.M. (1999). Teaching about communicating assessment results and grading. Educational measurement: issue and practice 18(1), 5-13

Brookhart, S.M. (2001). Successful students' formative and summative use of assessment information. Assessment in education 8,153-169

Brookhart, S.M. (2003). Developing measurement theory for classroom assessment purposes and uses. Educational measurement: issue and practice

Brown S. And Glaser A. (1999). Assessment Matters in higher Education: Choosing and Using Diverse Approaches. Great Britain: St. Edmunds bury press Ltd, SRHE and Open University press

Careless, D. (2004). Converting assessment into learning. Theoretical and Practical perspectives. Paper
Presented at Chinese University of Hong Kong. Unpublished

Diamond, R.M. (1998). Designing and

Assessing Courses and Curricula: A Practical Guide. Sanfrancisco: Jossey-Bass Inc

Filer, A. (2003). Assessment: Social Practice and Social Product. London: Rutledge

Filer, A. (2003). Socio-historical and cultural contexts of assessment policy. London: Routledge

Haladyna and Downing. (2004). Constructirrelevant in high stakes testing. Educational measurement: Issue and practice 23(1), 17-27

Hoover, H.D. (2003).Some common misconceptions about tests and testing.Educational measurement: issue and practice 22(1), 5-12

James, D. (2003).Making the graduate. Perspectives on student experience of assessment in higher education. In Ann Filer (2003). Assessment: Social practice and social product. London: Rutledge

Mcmillan, H.J. (2003). Understanding and improving teachers' classroom assessment decision making:

implication for theory and practice.Educational

measurement: issues and practice 22(4), 34-43 
Meherens, W.A., and Lehmann, J.I. (1991). Measurement and Evaluation in Education \& Psychology $\left(4^{\text {th }} e d\right)$. Wadsworth: Thomson learning

Nitko, A.J. (2004). Educational Assessment of Students $\left(4^{\text {th }} e d\right)$.Ohio: Merrill Prentice Hall

Pratt, D. (1998). Curriculum planning: A handbook for professionals. London: Harcourt Brace College Publishers

Shepard, L.M. (2001). The role of classroom assessment in teaching and learning. In V. Richardson(ed), Handbook of research on teaching $\left(4^{\text {th }}\right.$ ed). Washington: AERA

Smith, K.J. (2003).Reconsidering reliability in classroom assessment and grading. Educational measurement: issue and practice 22(4), 26-3.
Stiggins, R.J. (1992).Relevant classroom assessment training for teachers. Educational measurement: issue and practice 10 (1), 7-12

Stiggins, R.J. (2001).student-involved classroom assessment $\left(3^{\text {rd }}\right.$ ed). Upper Saddle River, NJ: Prentice Hall.

Wolf, D.P. (1993).Assessment as an episode of learning. In R.E. Bennet \& W.C. Ward (eds), Construction versus choice in cognitive measurement. Hilsadale, NJ: Lawrence Erlbaum.

Wright, et.al (1997).Teacher and classroom context effects on student achievement: Implication for teacher evaluation. Journal of personnel Evaluation in Education, 11, 57-67. 